\title{
Assessment of early renal angina index for prediction of subsequent severe acute kidney injury during septic shock in children
}

Linlin Huang ${ }^{1+}$, Ting Shi ${ }^{2 \dagger}$, Wei Quan ${ }^{3 \dagger}$, Weiming $\mathrm{Li}^{1}$, Lili Zhang ${ }^{3}$, Xueping $\mathrm{Liu}^{4}$, Saihu Huang ${ }^{1}$, Ying $\mathrm{Li}^{1}$ and Xiaozhong $\mathrm{Li}^{3^{*}}$

\begin{abstract}
Background: Acute kidney injury (AKI) is independently related to the adverse outcome of septic shock, but it lacks effective early predictors. Renal anginal index (RAI) was used to predict subsequent severe AKI (AKIs) in critically ill patients. The application of RAI in children with septic shock has not been reported. This study aims to evaluate the efficacy of early RAI in predicting subsequent AKIs within 3 days after PICU admission in children with septic shock by comparing with early fluid overload (FO) and early creatinine elevation.

Methods: Sixty-six children admitted to PICU aged 1 month to 16 years old, with septic shock from January 2016 to December 2019 were analyzed retrospectively. According to the 2012 Kidney Disease Improving Global outcomes $(K D I G O)$ criteria, AKIs was defined by the KDIGO stage $\geq 2$ within 3 days after PICU admission. Early RAl positive (RAl+) was defined as RAI $\geq 8$ within $12 \mathrm{~h}$ of PICU admission. Any elevation of serum creatinine (SCr) over baseline within $12 \mathrm{~h}$ after PICU admission was denoted as "Early SCr $>$ base". Early FO positive (FO+) was defined as FO > $10 \%$ within $24 \mathrm{~h}$ of PICU admission.

Results: Of 66 eligible cases, the ratio of early RAlt, early $\mathrm{SCr}>$ base, early FO+ was 57.57, 59.09 and 16.67\% respectively. The incidence of AKIs in early RAl+ group (78.94\%) was higher than that in early RAl- group (21.42\%) $(p=$ 0.04), and there was no significant difference compared with the early FO+ group (71.79\%) and early $\mathrm{SCr}>$ base group (81.82\%) $(P>0.05)$. After adjustment for confounders, early RAl+ was independently associated with the occurrence of AKls within 3 days (OR 10.04,95\%Cl 2.39-42.21, $p<0.01$ ). The value of early RAl+ (AUC $=0.78$ ) to identify patients at high risk of AKls was superior to that of early $\mathrm{SCr}>$ base $(\mathrm{AUC}=0.70)$ and early $\mathrm{FO}+(\mathrm{AUC}=0.58)$. A combination of serum lactate with early RAI+ improved the predictive performance for assessing AKIs (AUC $=0.83$ ).

Conclusions: Early RAI could be used as a more convenient and effective index to predict the risk of AKIs in children with septic shock within 3 days. Early RAl+ combined with serum lactate improved the predictive performance for assessing AKls.
\end{abstract}

Keywords: Acute kidney injury, Renal angina index, Septic shock, Predictor

\footnotetext{
*Correspondence: xiaozhonglisz@sohu.com

${ }^{\dagger}$ Linlin Huang, Ting Shi and Wei Quan contributed equally to this work.

${ }^{3}$ Department of Nephrology and Immunology, Children's Hospital of Soochow University, Suzhou, China

Full list of author information is available at the end of the article
}

C C The Author(s). 2020 Open Access This article is licensed under a Creative Commons Attribution 4.0 International License, which permits use, sharing, adaptation, distribution and reproduction in any medium or format, as long as you give appropriate credit to the original author(s) and the source, provide a link to the Creative Commons licence, and indicate if changes were made. The images or other third party material in this article are included in the article's Creative Commons licence, unless indicated otherwise in a credit line to the material. If material is not included in the article's Creative Commons licence and your intended use is not permitted by statutory regulation or exceeds the permitted use, you will need to obtain permission directly from the copyright holder. To view a copy of this licence, visit http://creativecommons.org/licenses/by/4.0/ The Creative Commons Public Domain Dedication waiver (http://creativecommons.org/publicdomain/zero/1.0/) applies to the data made available in this article, unless otherwise stated in a credit line to the data. 


\section{Background}

Acute kidney injury (AKI) often occurs early after PICU admission in patients with septic shock and the incidence is $59-72 \%$ [1-3]. During septic shock, decreased cortical renal perfusion was observed by renal contrastenhanced ultrasound, which is supposed to be part of the cause of AKIs [4]. AKIs is independently associated with increased morbidity and mortality [1]. Current management guidelines for patients with AKI recommend that early recognition of AKI risks and augmentation of supportive care will limit AKI progression [5].

According to the 2012 KDIGO criteria, the definition of AKI depends on serum creatinine and urine volume. The accuracy of any creatinine-based or urine volume-based classification is likely to be affected by age, pre-existing sarcopenia, catabolism and fluid intake and diuretic, respectively [5]. Due to the uncertainty of serum creatinine and urine volume, the diagnosis of AKI is often delayed, which creates great obstacles for effective early intervention. One of the ways to solve this problem is to combine other clinical indicators to alleviate the uncertainty of creatinine and urine volume in judging renal function.

The concept of renal angina index (RAI) combines risk factors and early signs of injury, intending to stratify patients at risk to avoid subsequent AKIs [6]. According to reports, RAI can improve accuracy for prediction of AKIs in critically ill children and young adults [7-9]. However, there are no reports of RAI used to predict AKI in patients with septic shock. Our aim of this study is to evaluate the efficacy of early RAI in predicting subsequent AKIs within 3 days after PICU in children with septic shock by comparing with early FO and early creatinine elevation.

\section{Methods}

\section{Study design and participants}

This study was conducted at the children's hospital of Soochow University, a tertiary pediatric hospital from China. The study was approved by the Ethics Committee of Children's Hospital of Soochow University, and granted a waiver of informed consent. All hospitalized patients aged 1 month to 16 years old who were diagnosed with septic shock in PICU from January 2016 to December 2019 were retrospectively reviewed. Deep A et al. found that most patients developed AKI within the first $48 \mathrm{~h}$ of PICU admission [1]. So, patients with previously known kidney diseases, patients with hospital stay less than $48 \mathrm{~h}$, patients who developed AKI 3 days after PICU admission and AKIs within $12 \mathrm{~h}$ after PICU admission were excluded.

\section{Data collection}

Electronic records were reviewed. Data were collected on demographics, medical history, current illness, laboratory variables, pediatric scores of critical illness (PRISM III score and PELOD-2 score) at the first day of PICU admission. Data was also recorded as follow: fluid balance, PICU and hospital lengths of stay, need for mechanical ventilation (MV) and renal replacement therapy (RRT), early vasoactive support (early VS), AKI stage within 3 days after PICU admission and follow-up.

\section{Definition}

Baseline serum creatinine ( $\mathrm{SCr}$ ) was considered as the lowest $\mathrm{SCr}$ in the 3 months before admission. When baseline $\mathrm{SCr}$ was unavailable, a baseline serum creatinine was calculated by the Schwartz formula with an estimated glomerular filtration (eGFR) of $120 \mathrm{ml} / \mathrm{min} /$ $1.73 \mathrm{~m}^{2}$ [10]. For both RAI and elevated creatinine determination, maximum $\mathrm{SCr}$ in the first $12 \mathrm{~h}$ of PICU admission was used. Elevated $\mathrm{SCr}$ within $12 \mathrm{~h}$ after PICU admission was denoted as "early $\mathrm{SCr}>$ base".

Early RAI was defined as the product of risk group score and renal injury score, calculated base on clinical data in the first $12 \mathrm{~h}$ of PICU admission. We adopted the RAI model proposed by Basu et al. in 2018 [8]. Risk strata include PICU admission, solid organ or stem-cell transplantation, MV and vasoactive support. Injury strata contains creatinine elevation and FO. It is worth noting that small changes in serum creatinine of less than 1.5 times are concerned, which is different from the definition of creatinine in the KDIGO criteria on AKI. The index $\geq 8$ was considered RAI + , and the score $<$ 8 was defined as RAI-. The method of calculation was shown in Table 1 [8].

Early fluid overload (FO) was calculated $24 \mathrm{~h}$ after admission with the formula as follow [11]: percentage of FO $(\%)=$ [total fluid in(L)-total fluid out(L)]/ admission body weight $(\mathrm{kg}) \times 100$. It has been reported that $\mathrm{FO}>10 \%$ is related to higher mortality in children with septic shock [12]. $\mathrm{FO}>10 \%$ was defined as $\mathrm{FO}+$, otherwise it was FO-.

AKI was defined and classified according to the 2012 KDIGO criteria. AKIs was defined by the KDIGAO stage $\geq 2$ within 3 days after PICU admission. Patients with AKIs (KDIGO Stage 2-3) were divided into AKIs group, otherwise non-AKIs group.

Septic shock was defined as sepsis-induced hypotension persisting despite adequate fluid resuscitation [13]. Vasoactive support is required to maintain an appropriate mean arterial pressure in patients with septic shock. The need for vasoactive support within $12 \mathrm{~h}$ of PICU hospitalization was defined as early VS.

\section{Statistical analysis}

Continuous variables with symmetric distribution were presented as the mean \pm standard deviation (SD), while asymmetric distribution with median and interquartile (IQR). Categorical variables were expressed as frequency and percentage. Continuous variables with a normal 
Table 1 The Renal Angina Index

\begin{tabular}{|c|c|c|c|}
\hline \multicolumn{2}{|l|}{ Risk strata } & Score & \\
\hline \multicolumn{2}{|l|}{ Admission to PICU } & 1 & \\
\hline \multicolumn{2}{|c|}{ Solid organ Or Stem-cell transplantation } & 3 & \\
\hline \multicolumn{2}{|c|}{ Mechanical ventilation Or Vasoactive support or both } & 5 & \\
\hline Injury strata & & & Risk $\times$ injury scores: $1-40$ \\
\hline $\mathrm{SCr} /$ base & \%FO accumulation & & \\
\hline Decreased or no change & $<5 \%$ & 1 & \\
\hline$>1 \times-1.49 x$ & $5-10 \%$ & 2 & \\
\hline $1.5 \times-1.99 x$ & $10-15 \%$ & 4 & \\
\hline$\geq 2 \times$ & $>15 \%$ & 8 & \\
\hline
\end{tabular}

Renal angina index (RAl) was calculated basing on the clinical data within the first $12 \mathrm{~h}$ after PICU admission. And RAI $\geq 8$ was defined as RAl positive PICU pediatric intensive care unit, $\mathrm{SCr}$ serum creatinine, FO fluid overload

distribution were compared between groups using Student's t-test, and with a nonnormal distribution using the Wilcoxon ranked test. Statistical significance of differences between categorical variables was evaluated using the chisquared test. Logistic regression was used to identify predictors for subsequent AKIs within 3 days after PICU admission. The efficiency of risk factors for predicting AKIs was evaluated by the area under the curve (AUC) of the receiver operating characteristic (ROC) curve. All the analyses were conducted in IBM-SPSS version 25(IBM corporation, Armonk, New York, USA), and $p<0.05$ from 2sided tests was considered statistically significant.

\section{Results}

\section{Patients characteristics}

Of the total 84 patients with septic shock admitted to PICU during the period, 66 patients met the requirement of this study and there was no missing data. (Fig. 1). Eighteen patients were excluded for the following reasons: hospital stay less than $48 \mathrm{~h}(n=3)$, previously known kidney disease $(n=5)$, developed AKI 3 days after $\operatorname{admission}(n=4)$, AKIs within $12 \mathrm{~h}$ of PICU admission $(n=6)$. Of all the eligible cases, age was 58.00 (8.50-131.75) months, 44(66.70\%) were male, 36(54.50\%) developed AKIs within 3 days after PICU admission, 37 (56.60\%) needed MV, 16(24.24\%) needed RRT, 38(57.60\%) needed early VS, $41(62.10 \%)$ had underlying diseases and $27(40.90 \%)$ died. The most common infection foci were respiratory tract (54.54\%), followed by gastrointestinal infections $(28.79 \%)$. According to the $2012 \mathrm{KDIGO}$ criteria, 53(80.30\%) patients developed AKI: 17 (32.08\%) stage1, 5 (9.43\%) stage2, and 31 (58.49\%) stage3.

\section{Patients who died had a higher incidence of AKIs}

The incidence of AKIs in the non-survivors (92.59\%) was higher than that in the survivors $(28.21 \%)(p<0.01)$. The proportion of patients without AKI in nonsurvivors $(3.70 \%)$ was lower than that in the survivors $(30.77 \%)(p=0.02)$. (Table 2).

\section{The ratio of early $\mathrm{RAl}+$, early $\mathrm{SCr}>$ base, early $\mathrm{FO}+$ was higher in AKIs group}

The age (57.00 (2.00-137.00) months vs. 59.00 (16.50$124.00)$ months, $p=0.68)$, percentage of males $(66.67 \%$

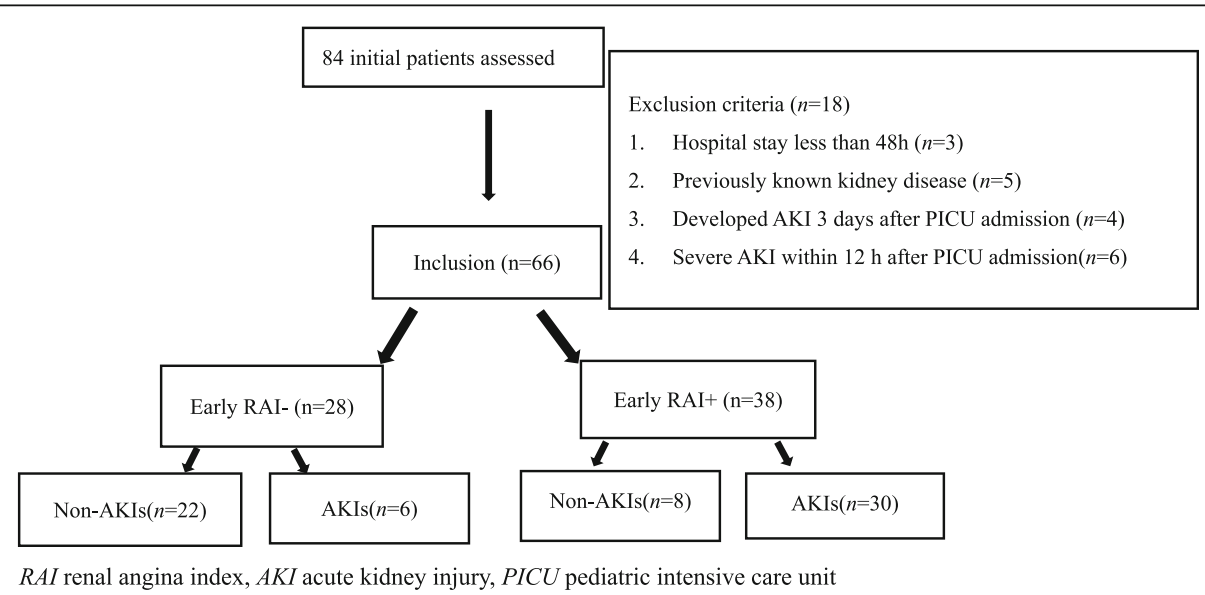

Fig. 1 Flow of participants in the study 
vs. $66.67 \%, p=1)$, and underlying disease $(50.00 \%$ vs. $72.22 \%, p=0.06$ ) was similar between non-AKIs group and AKIs group. Compared with non-AKIs group, the baseline laboratory results such as serum lactate (4.00 (2.80-9.10) $\mathrm{mmol} / \mathrm{L}$ vs. $2.80(1.65-3.87) \mathrm{mmol} / \mathrm{L}, p=$ $0.01)$, active partial thromboplastin time $(55.85$ $(48.15-76.17)$ s vs. $46.20(37.05-51.77)$ s, $p<0.01)$ were increased in AKIs group, and serum albumin $(30.38 \pm 7.35 \mathrm{~g} / \mathrm{L}$ vs. $33.92 \pm 6.09 \mathrm{~g} / \mathrm{L}, p=0.04)$, platelet count $\left(32.00(15.00-83.25) \times 10^{9} / \mathrm{L}\right.$ vs. $225.50(30.75-$ $\left.316.00) \times 10^{9} / \mathrm{L}, p<0.01\right)$ decreased. The AKIs group had higher PRISM III score (14.00 (12.00-18.00) vs. $6.00(3.00-12.00), \quad p<0.01), \quad$ PELOD-2 score $(7.00$ (4.00-9.75)vs. $3.00(2.00-5.25), \quad p<0.01)$; increased utilization of RRT (36.11\% vs.10.00\%, $p=0.01)$, MV $(77.78 \%$ vs.30.00\%, $p<0.01)$, early VS $(80.56 \%$ vs. $30.00 \%, p<0.01)$; and increased mortality $(69.44 \%$ vs. $6.67 \%, p<0.01)$. Three patients in non-AKIs group had RRT due to fluid overload. The ratio of early $\mathrm{SCr}>$ base $(77.78 \%$ vs. $36.67 \%, p<0.01)$, early RAI+ (83.33\% vs. $26.67 \%, p<0.01)$, and early $\mathrm{FO}+(25.00 \%$ vs. $6.67 \%, p=0.04$ ) was higher in AKIs group. (Table 3).

The patients with early RAI+ had higher incidence of AKIs and poor outcomes

Early RAI+ occurred in 38/66 (57.57\%) of patients. Compared to early RA- group, early RA+ group had higher PRISM III score (14.00 (12.00-18.25) vs. 6.50 (3.009.00), $p<0.01)$ and PELOD-2 score (7.00 (4.00-9.00) vs.3.00 (2.00-4.00), $p<0.01)$. Early RAI+ group was associated with a higher incidence of MV (73.68\% vs. $32.14 \%, p<0.01)$, RRT (34.21\% vs.10.71\%, $p=0.02$ ), early VS (73.68\% vs. $35.71 \%, p=0.02)$, and increased mortality (57.89\% vs. $17.85 \%, p<0.01)$. The proportion of AKIs in early RAI+ group (78.94\%) was higher than that in early RAI- group $(21.42 \%)(p=0.04)$. (Table 4$)$.

Table 2 Incidence of AKI within 3 days after PICU admission between survivors and non-survivors

\begin{tabular}{llll}
\hline Variable & Survivors $(n=39)$ & Non-survivors $(n=27)$ & $p$-value \\
\hline Non-AKI, $n(\%)$ & $12(30.77)$ & $1(3.70)$ & 0.02 \\
Stage $1, n(\%)$ & $16(41.03)$ & $1(3.70)$ & 0.01 \\
Stage2, $n(\%)$ & $4(10.25)$ & $1(3.70)$ & 0.32 \\
Stage3, $n(\%)$ & $7(17.95)$ & $24(88.90)$ & $<0.01$ \\
Severe AKI, $n(\%)$ & $11(28.21)$ & $25(92.59)$ & $<0.01$ \\
Early RAI+, $n(\%)$ & $16(41.02)$ & $22(81.48)$ & $<0.01$ \\
Early FO+, $n(\%)$ & $3(7.69)$ & $8(29.63)$ & 0.02 \\
Early SCr $>$ base, $n(\%)$ & $20(51.28)$ & $19(70.37)$ & 0.12
\end{tabular}

$A K I$ acute kidney injury, $R A I$ renal angina index, $F O$ fluid overload, $S C r$ serum creatinine
The incidence of AKIs in early $\mathrm{SCr}>$ base group and early $\mathrm{FO}+$ group was similar to that in early $\mathrm{RAI}+$ group

The incidence of early $\mathrm{RAI}+$, early $\mathrm{SCr}>$ base and early $\mathrm{FO}+$ was 38/66 (57.57\%), 39/66 (59.09\%) and 11/ $66(16.67 \%)$, respectively. Table 5 showed that PRISM III score (14.00 (12.00-18.25) vs. 13.00 (9.00-17.00) vs. $17.00(12.00-19.00), p=0.43)$ and PELOD-2 score (7.00 (4.00-9.00) vs. $5.00(3.00-10.00)$ vs. 6.00 (4.00-9.00), $p=0.37)$ were similar in three groups. The proportion of MV (73.68\% vs. $64.10 \%$ vs. $81.82 \%, p=0.44)$, RRT (34.21\% vs. $30.76 \%$ vs.27.27\%, $p=0.89)$, early VS $(73.68 \%$ vs. $66.66 \%$ vs. $72.73 \%, p=0.78$ ) and mortality (57.68\% vs. $48.72 \%$ vs. $72.73 \%, p=0.34$ ) did not demonstrate a significant difference among groups. Early RAI+ group, early $\mathrm{SCr}>$ base group, and early $\mathrm{FO}+$ group demonstrated a similar ratio of AKIs $(78.94 \%$ vs. $71.79 \%$ vs. $81.82 \%, p=0.68)$.

The prediction value of early RAI+ for AKIs in children with septic shock was significantly higher than that of early $\mathrm{FO}+$ and early $\mathrm{SCr}>$ base

Univariate regression analysis done to evaluate the effect of individual parameters showed that early RAI+, early SCr $>$ base, PRISM III score, PELOD-2 score, MV, early VS, serum albumin, serum lactate were significantly associated with the occurrence of AKIs within 3 days after admission to PICU $(p<0.05)$. Multivariate analysis showed that only early RAI+ (OR 10.04, 95\%CI 2.39-42.21, $p<$ 0.01 ), early VS (OR 9.08, 95\%CI 2.10-39.22, $p<0.01$ ), serum lactate (OR 1.24, 95\%CI 1.03-1.50, $p=0.02$ ) were independently associated with the occurrence of AKIs within 3 days (Table 6). The value of early RAI+ (AUC $0.78,95 \%$ CI $0.65-0.89, p<0.01)$ to identify patients at high risk of AKIs was superior to that of early $\mathrm{SCr}>$ base (AUC $0.70,95 \% C I$ 0.56-0.83, $p<0.01$ ) and early FO+ (AUC $0.58,95 \%$ CI 0.44-0.72, $p=0.24$ ). (Fig. 2).

\section{Early RAI+ combined with serum lactate improved the predictive performance for assessing AKIs}

Logistic analysis showed that early RAI+ and serum lactate were associated with incidence of AKIs. AUC of serum lactate for predicting AKIs was 0.69 (95\% CI $0.57-0.82, p=0.01$ ) with optimal cut-off $4.80 \mathrm{mmol} / \mathrm{L}$. A combination of serum lactate with early RAI+ improved the predictive performance for assessing AKIs (AUC 0.83, 95\% CI 0.73-0.93, $p<0.01$ ) (Fig. 2).

\section{Discussion}

Our retrospective study revealed that early RAI measured within the first $12 \mathrm{~h}$ of PICU admission was able to predict the development of secondary AKIs in children with septic shock and the value of early RAI+ in distinguishing the risk of AKIs was better than early $\mathrm{SCr}>$ base and early $\mathrm{FO}+$. 
Table 3 Baseline laboratory and patient characteristics between Non-AKIs and AKIs

\begin{tabular}{|c|c|c|c|}
\hline Variable & Non-AKIs $(n=30)$ & $\operatorname{AKIs}(n=36)$ & $p$-value \\
\hline Age in months & $57.00(2.00-137.00)$ & $59.00(16.50-124.00)$ & 0.68 \\
\hline Male, $n(\%)$ & $20(66.67)$ & $24(66.67)$ & 1.00 \\
\hline Underlying disease, $n$ (\%) & $15(50.00)$ & $26(72.22)$ & 0.06 \\
\hline Early SCr > base, $n(\%)$ & $11(36.67)$ & $28(77.78)$ & $<0.01$ \\
\hline Early RAl+, $n$ (\%) & $8(26.67)$ & $30(83.33)$ & $<0.01$ \\
\hline Early FO+, n (\%) & $2(6.67)$ & $9(25.00)$ & 0.04 \\
\hline \multicolumn{4}{|l|}{ Baseline laboratory Results } \\
\hline Serum albumin $(g / L)$ & $33.92 \pm 6.09$ & $30.38 \pm 7.35$ & 0.04 \\
\hline Serum chloride (mmol/L) & $102.17 \pm 4.79$ & $102.46 \pm 10.66$ & 0.89 \\
\hline Serum lactate (mmol/L) & $2.80(1.65-3.87)$ & $4.00(2.80-9.10)$ & 0.01 \\
\hline Active partial thromboplastin time (s) & $46.20(37.05-51.77)$ & $55.85(48.15-76.17)$ & $<0.01$ \\
\hline Thromboplastin time (s) & $16.90(14.42-18.85)$ & $18.85(16.02-24.77)$ & 0.01 \\
\hline Leukocyte count $\left(10^{9} / L\right)$ & $10.61 \pm 18.35$ & $13.68 \pm 22.46$ & 0.55 \\
\hline Hemoglobin (g/L) & $94.43 \pm 29.80$ & $85.75 \pm 29.25$ & 0.24 \\
\hline Platelet count $\left(\times 10^{9} / \mathrm{L}\right)$ & $225.50(30.75-316.00)$ & $32.00(15.00-83.25)$ & $<0.01$ \\
\hline \multicolumn{4}{|l|}{ Severity of Illness } \\
\hline PRISM III score & $6.00(3.00-12.00)$ & $14.00(12.00-18.00)$ & $<0.01$ \\
\hline PELOD-2 score & $3.00(2.00-5.25)$ & $7.00(4.00-9.75)$ & $<0.01$ \\
\hline Mechanical ventilation, $n(\%)$ & $9(30.00)$ & $28(77.78)$ & $<0.01$ \\
\hline Renal replacement therapy, $n(\%)$ & $3(10.00)$ & $13(36.11)$ & 0.01 \\
\hline Early VS, $n(\%)$ & $9(30.00)$ & $29(80.56)$ & $<0.01$ \\
\hline \multicolumn{4}{|l|}{ Outcomes } \\
\hline ICU LOS (d) & $8.50(4.00-10.00)$ & $5.50(4.50-8.00)$ & 0.06 \\
\hline Hospital LOS (d) & $19.50(17.00-28.25)$ & $17.50(5.00-24.00)$ & 0.03 \\
\hline Mortality $n(\%)$ & $2(6.67)$ & $25(69.44)$ & $<0.01$ \\
\hline
\end{tabular}

AKI acute kidney injury, RAI renal angina index, FO fluid overload, SCr serum creatinine, PRISM III pediatric risk of mortality III, LOS length of stay, PELOD-2 pediatric logistic organ dysfunction-2, PICU pediatric intensive care unit, VS vasoactive support

AKI is one of the common complications of septic shock. The mechanism of AKI in septic shock is complex. Hypoperfusion is the direct cause of AKI caused by septic shock. Disturbance of other system functions caused by hypoperfusion, such as abnormal blood coagulation, can also induce AKI. Compared with the nonAKIs group, patients with AKIs in this study had higher serum lactate concentration and active partial thromboplastin time, which reflected the status of tissue perfusion and coagulation, respectively. Some treatments such as MV [14] and vasoactive support [15] are related to AKI, and this study also found that the proportion of MV and early VS in the AKIs group was higher than that in the non-AKIs group. AKIs is independently associated with poor outcomes in children with septic shock [16]. Early prediction of AKIs can improve the prognosis of critical patients. Creatinine elevation and urine output is the most widely used and convenient index to evaluate renal function. However, they have limitations. Therefore, it is urgent to find novel evaluation indexes of AKI.
The concept of renal angina index (RAI) combines risk factors and early signs of injury, which has been validated and improved to predict AKIs. RAI $\geq 8$ is defined as RAI+, and it has been proved to be associated with AKIs and worse prognosis in critically ill patients $[7,8$, 17]. The incidence of AKIs in early RAI+ group was higher than that in early RAI- group in our study. We also observed that the patients in the early RAI+ group were more serious with higher mortality and needed more MV, RRT and early VS. It has been reported that the incorporation of other indicators of kidney injury can further increase the predictive power of RAI. Fluid overload [18], urinary neutrophil gelatinase-associated lipocalin [19] and urinary L-type fatty acid-binding protein [20] combined with RAI have been shown to optimize AKI prediction in critically ill patients.

As a component of RAI, FO is also used as an indicator of disease severity. FO represents the states of fluid balance, which comprehensively reflects fluid intake, cardiovascular function and renal function. Kelm DJ et al. 
Table 4 The severity of illness and outcomes between early RAI- group and early RAI+ group

\begin{tabular}{|c|c|c|c|}
\hline Variable & Early RAI- $(n=28)$ & Early RAI+ $(n=38)$ & $p$-value \\
\hline Age in months & $71.00(5.50-134.00)$ & $57.00(10.00-132.00)$ & 0.88 \\
\hline Male, $n(\%)$ & $20(71.42)$ & $24(63.15)$ & 0.48 \\
\hline Underlying disease, $n$ (\%) & $15(53.57)$ & $26(68.42)$ & 0.21 \\
\hline Early SCr > base, $n(\%)$ & $9(32.14)$ & $30(78.94)$ & $<0.01$ \\
\hline Early FO+, $n(\%)$ & $3(10.71)$ & $8(21.05)$ & 0.26 \\
\hline \multicolumn{4}{|l|}{ Severity of IIness } \\
\hline PRISM III score & $6.50(3.00-9.00)$ & $14.00(12.00-18.25)$ & $<0.01$ \\
\hline PELOD-2 score & $3.00(2.00-4.00)$ & $7.00(4.00-9.00)$ & $<0.01$ \\
\hline Mechanical ventilation, $n(\%)$ & $9(32.14)$ & $28(73.68)$ & $<0.01$ \\
\hline Renal replacement therapy, $n(\%)$ & $3(10.71)$ & $13(34.21)$ & 0.02 \\
\hline Early VS, $n$ (\%) & $10(35.71)$ & $28(73.68)$ & 0.02 \\
\hline \multicolumn{4}{|c|}{ AKI incidence within 1 week after admission to PICU } \\
\hline $\mathrm{NO} A \mathrm{AKI}, n(\%)$ & $12(42.85)$ & $1(2.63)$ & $<0.01$ \\
\hline Stage $1, n(\%)$ & $10(35.71)$ & $7(18.43)$ & 0.11 \\
\hline Stage2, $n(\%)$ & $2(7.14)$ & $3(7.89)$ & 0.91 \\
\hline Stage $3, n(\%)$ & $4(14.28)$ & $27(73.68)$ & $<0.01$ \\
\hline Severe AKI, $n(\%)$ & $6(21.42)$ & $30(78.94)$ & 0.04 \\
\hline \multicolumn{4}{|l|}{ Outcomes } \\
\hline ICU LOS (d) & $7.50(4.00-10.75)$ & $5.50(3.50-9.00)$ & 0.11 \\
\hline Hospital LOS (d) & $20.50(16.50-27.75)$ & $17.00(8.00-26.50)$ & 0.14 \\
\hline Mortality n (\%) & $5(17.85)$ & $22(57.89)$ & $<0.01$ \\
\hline
\end{tabular}

AKI acute kidney injury, RAI renal angina index, FO fluid overload, SCr serum creatinine, PRISM III pediatric risk of mortality III, LOS length of stay, PELOD2 pediatric logistic organ dysfunction-2, PICU pediatric intensive care unit, VS vasoactive support

Table 5 Early RAI+ versus early $\mathrm{SCr}>$ base versus early FO+

\begin{tabular}{|c|c|c|c|c|}
\hline Variable & Early RAI+ $(n=38)$ & Early SCr $>$ base $(n=39)$ & Early FO+ $(n=11)$ & $p$-value \\
\hline Age in months & $57.00(10.00-132.00)$ & $51.50(8.50-132.00)$ & $60.00(21.50-125.00)$ & 0.98 \\
\hline Male, $n(\%)$ & $24(63.15)$ & $25(64.10)$ & $8(72.73)$ & 0.83 \\
\hline Underlying disease, $n$ (\%) & $26(68.42)$ & $24(61.53)$ & $8(72.73)$ & 0.71 \\
\hline \multicolumn{5}{|l|}{ Severity of Illness } \\
\hline PRISM III score & $14.00(12.00-18.25)$ & $13.00(9.00-17.00)$ & $17.00(12.00-19.00)$ & 0.43 \\
\hline PELOD-2 score & $7.00(4.00-9.00)$ & $5.00(3.00-10.00)$ & $6.00(4.00-9.00)$ & 0.37 \\
\hline Mechanical ventilation, $n(\%)$ & $28(73.68)$ & $25(64.10)$ & $9(81.82)$ & 0.44 \\
\hline Renal replacement therapy, $n$ (\%) & $13(34.21)$ & $12(30.76)$ & $3(27.27)$ & 0.89 \\
\hline Early VS, n (\%) & $28(73.68)$ & $26(66.66)$ & $8(72.73)$ & 0.78 \\
\hline \multicolumn{5}{|c|}{ AKI incidence within 1 week after admission to PICU } \\
\hline $\mathrm{NO} A K I, n(\%)$ & $1(2.63)$ & $1(2.57)$ & $2(18.18)$ & 0.06 \\
\hline Stage $1, n(\%)$ & $7(18.43)$ & $10(25.64)$ & $0(0.00)$ & 0.16 \\
\hline Stage2, $n(\%)$ & $3(7.89)$ & $3(7.69)$ & $1(9.09)$ & 0.98 \\
\hline Stage $3, n(\%)$ & $27(71.05)$ & $25(64.10)$ & $8(72.73)$ & 0.76 \\
\hline Severe AKI, $n(\%)$ & $30(78.94)$ & $28(71.79)$ & $9(81.82)$ & 0.68 \\
\hline \multicolumn{5}{|l|}{ Outcomes } \\
\hline ICU LOS (d) & $5.50(3.50-9.00)$ & $5.00(4.00-11.00)$ & $4.00(3.5-7.00)$ & 0.94 \\
\hline Hospital LOS (d) & $17.00(8.00-26.50)$ & $19.00(9.00-24.00)$ & $19.00(1.00-37.00)$ & 0.89 \\
\hline Mortality n (\%) & $22(57.89)$ & 19 (48.72) & 8 (72.73) & 0.34 \\
\hline
\end{tabular}


Table 6 Logistic regression analysis for severe acute kidney injury

\begin{tabular}{|c|c|c|c|c|c|c|}
\hline \multirow[t]{2}{*}{ variable } & \multicolumn{3}{|c|}{ Univariate analysis } & \multicolumn{3}{|c|}{ Multivariate analysis } \\
\hline & $\overline{\mathrm{OR}}$ & $95 \% \mathrm{Cl}$ & $p$-value & $\overline{\mathrm{OR}}$ & $95 \% \mathrm{Cl}$ & $p$-value \\
\hline Early RAl+ & 13.75 & $4.17-45.33$ & $<0.01$ & 10.04 & $2.39-42.21$ & $<0.01$ \\
\hline Early $\mathrm{SCr}>$ base & 6.04 & $2.05-17.82$ & $<0.01$ & & & \\
\hline Early FO+ & 4.66 & $0.92-23.62$ & 0.06 & & & \\
\hline PRISM III score & 1.26 & $1.12-1.42$ & $<0.01$ & & & \\
\hline PELOD-2 score & 1.47 & $1.21-1.80$ & $<0.01$ & & & \\
\hline Underlying disease & 2.60 & $0.93-7.22$ & 0.06 & & & \\
\hline MV & 8.16 & $2.69-24.72$ & $<0.01$ & & & \\
\hline Early VS & 11.27 & $3.48-36.54$ & $<0.01$ & 9.08 & $2.10-39.22$ & $<0.01$ \\
\hline Serum albumin & 0.92 & $0.85-0.998$ & 0.04 & & & \\
\hline Serum chloride & 1.00 & $0.94-1.06$ & 0.88 & & & \\
\hline Serum lactate & 1.24 & $1.04-1.48$ & 0.01 & 1.24 & $1.03-1.50$ & 0.02 \\
\hline
\end{tabular}

RAI renal angina index, FO fluid overload, SCr serum creatinine, PRISM III pediatric risk of mortality III, LOS length of stay, PELOD-2 pediatric logistic organ

dysfunction-2, $C l$ confidence interval, $O R$ odds ratio, $M V$ mechanical ventilation, $V S$ vasoactive support

suggested that persistent FO was associated with increased use of fluid-related medical intervention and hospital mortality in patients with severe sepsis and septic shock [21]. FO for more than 2 days increased the risk of kidney failure in children with septic shock [22]. Another study has shown that $\mathrm{FO}>10 \%$ is related to a higher mortality [12]. In this study, the incidence of early $\mathrm{FO}+$ was higher in non-survivors and AKIs group than that in survivors and
non-AKIs group, respectively. However, our results showed that early $\mathrm{FO}+$ was not a sensitive indicator for predicting AKIs in patients with septic shock.

Previous reports on predicting AKIs by RAI were mainly aimed at critical patients in ICU, but little attention focused on patients with septic shock alone. In this study, the feasibility of predicting AKIs by early RAI+ was discussed by comparing with early creatinine elevation and

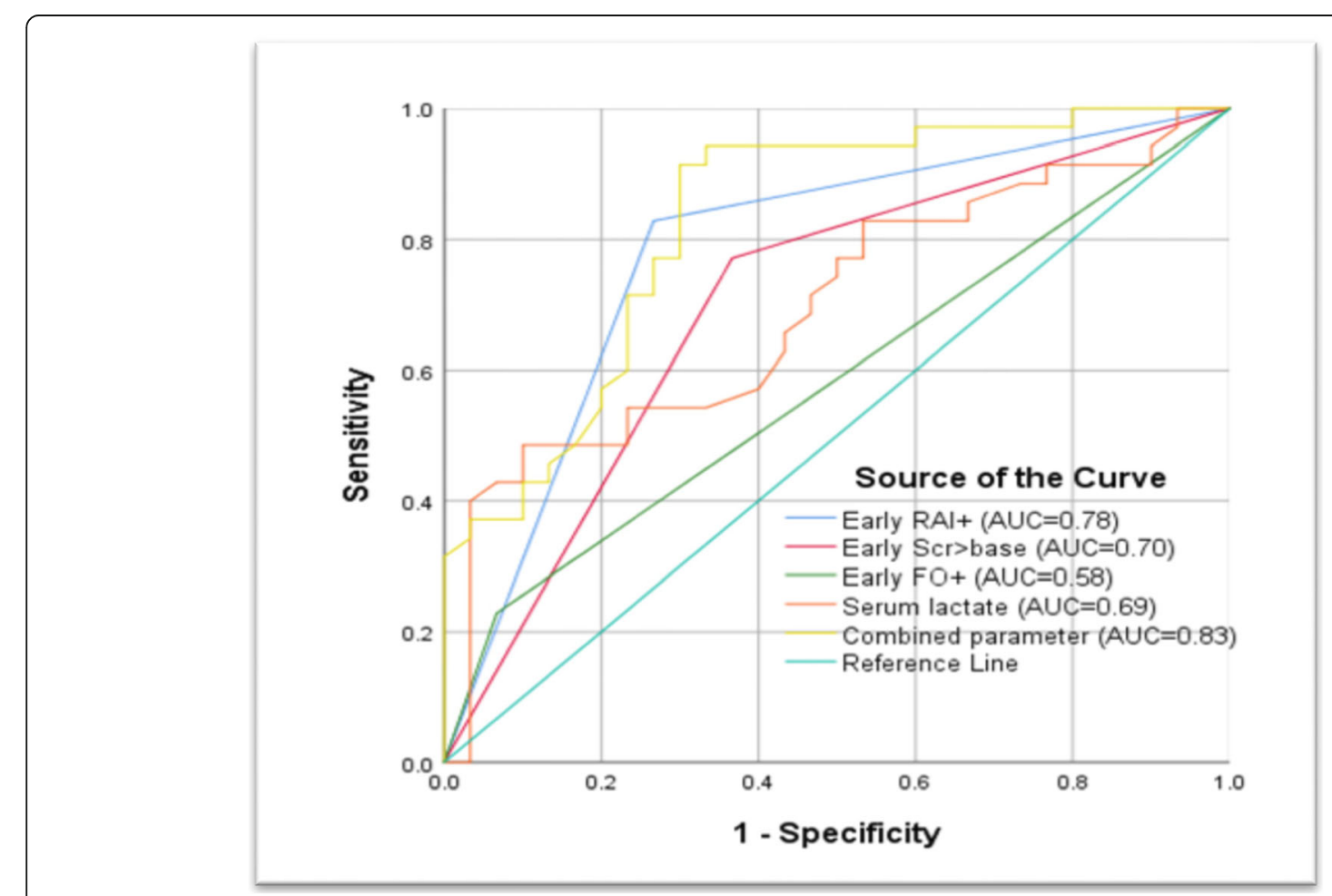

Fig. 2 Receiver operating characteristic (ROC) curves for prediction of severe acute kidney injury. RAl renal angina index, FO fluid overload, SCr serum creatinine, AUC the area under the curve. Combined parameter: early RAI+ and serum lactate 
early $\mathrm{FO}+$. The incidences of early $\mathrm{RAI}+$, early $\mathrm{SCr}>$ base and early FO+ were 57.57, 59.09 and 16.67\%, respectively. We found that early RAI+ demonstrated better prediction for AKIs than early $\mathrm{FO}+$ and early $\mathrm{SCr}>$ base in children with septic shock. The performance of early RAI+ and early $\mathrm{SCr}>$ base in predicting AKIs in our study were parallel with that in critically ill patients $[8,9]$. The reason why RAI is better than $\mathrm{FO}$ and $\mathrm{SCr}>$ base in predicting AKIs maybe that RAI combines early signs of renal injury with the risk factors. Early RAI+ was also associated with higher mortality, MV, RRT and early VS in this study. Therefore, early renal protection intervention should be necessary for patients with RAI+.

In addition to early $\mathrm{RAI}+$, serum lactate was also independently associated with AKIs within 3 days of PICU admission in our study. Inclusion of serum lactate with early RAI+ improved the predictive performance for assessing AKIs (AUC:0.83). Elevated serum lactate indicates microcirculation disorder, and can also reflect the status of renal microcirculation, which could be used to further improve the strata of renal injury in the RAI score. The RAI model is still being improved to facilitate operation and improve detection accuracy. Hanson HR et al. reported an acute RAI model for ruling out the development of in-hospital AKI at emergency department [23].

Our study has several limitations. First, the retrospective nature of this study was its greatest limitation because the results depended on the accuracy and completeness of patient records. Second, baseline serum creatinine was not available in some patients, which was estimated by the Schwartz formula with an estimated glomerular filtration (eGFR) of $120 \mathrm{ml} / \mathrm{min} / 1.73 \mathrm{~m}^{2}$. Third, it is a small sample study, further randomized and controlled clinical trials are needed to determine the efficacy of RAI in predicting AKIs in children with septic shock.

\section{Conclusions}

The incidence of AKIs in patients with early RAI+ reached $78.94 \%$. Patients with early RAI+ were in serious condition with higher mortality, needed more MV, RRT and early VS. Compared with context-free changes in early SCr and early FO, early RAI+ could be used as a more convenient and effective index to predict the risk of AKIs in children with septic shock. Inclusion of serum lactate with early RAI+ improved the predictive performance for assessing AKIs.

\section{Abbreviations}

AKI: Acute kidney injury; AKIs: Severe acute kidney injury; RAI: Renal anginal index; FO: Fluid overload; eGFR: Estimated glomerular filtration; SCr: Serum creatinine; BUN: Serum urea nitrogen; UA: Uric acid; VS: Vasoactive support; WBC: White blood cell; CRP: C-reactive protein; PCT: Procalcitonin; RRT: Renal replacement therapy; MV: Mechanical ventilation; PRISM III: Pediatric risk of mortality III; PELOD-2: Pediatric logistic organ dysfunction-2; PICU: Pediatric intensive care unit

\section{Acknowledgements}

Not applicable.

\section{Authors' contributions}

$\mathrm{LH}$ : designed the study, participated in data collection and cleaning, performed the analysis, and drafted the manuscript; XL: contributed to conception and design of the study, and critically revised the manuscript; TS and WQ: contributed to acquisition, analysis and interpretation of data, and critically revised the manuscript; $\mathrm{WL}, \mathrm{LZ}, \mathrm{XL}$ and $\mathrm{SH}$ : contributed to acquisition and analysis of data; YL: contributed to critically revised the manuscript. All authors read and approved of the final manuscript.

\section{Funding}

This work was supported by the following: National Natural Science Foundation of China (81370787), Jiangsu Provincial Special Program of Medical Science (SBL2014030237), Key Laboratory of Children Kidney Pathology in Suzhou (SZS201511). The funding bodies had no role in the design of the study and collection, analysis and interpretation of data and in writing the manuscript.

\section{Availability of data and materials}

All data generated or analyzed during this study are included in this published article.

\section{Ethics approval and consent to participate}

The study was approved by the Ethics Committee of Children's Hospital of Soochow University, and granted a waiver of informed consent.

\section{Consent for publication}

Not applicable.

\section{Competing interests}

The authors declare that they have no competing interests.

\section{Author details}

${ }^{1}$ Pediatric Intensive Care Unit, Children's Hospital of Soochow University, Suzhou, China. ${ }^{2}$ Department of Epidemiology, Children's Hospital of Soochow University, Suzhou, China. ${ }^{3}$ Department of Nephrology and Immunology, Children's Hospital of Soochow University, Suzhou, China. ${ }^{4}$ Department of Anesthesiology, Children's Hospital of Soochow University, Suzhou, China.

Received: 25 April 2020 Accepted: 16 August 2020

Published online: 20 August 2020

References

1. Deep A, Sagar H, Goonasekera C, Karthikeyan P, Brierley J, Douiri A. Evolution of acute kidney injury and its association with systemic hemodynamics in children with fluid-refractory septic shock. Crit Care Med. 2018;46(7):e677-83.

2. Medeiros P, Nga HS, Menezes P, Bridi R, Balbi A, Ponce D. Acute kidney injury in septic patients admitted to emergency clinical room: risk factors and outcome. Clin Exp Nephrol. 2015;19(5):859-66.

3. Bu X, Zhang L, Chen P, Wu X. Relation of neutrophil-to-lymphocyte ratio to acute kidney injury in patients with sepsis and septic shock: a retrospective study. Int Immunopharmacol. 2019;70:372-7.

4. Harrois A, Grillot N, Figueiredo S, Duranteau J. Acute kidney injury is associated with a decrease in cortical renal perfusion during septic shock. Crit Care. 2018;22(1):161.

5. Khwaja A. KDIGO clinical practice guidelines for acute kidney injury. Nephron Clin Pract. 2012;120(4):c179-84.

6. Goldstein SL, Chawla LS. Renal angina. Clin J Am Soc Nephrol. 2010;5(5): 943-9.

7. Kaur R, Dhooria GS, Pooni PA, et al. Utilization of the renal angina index in PICU of a developing country for prediction of subsequent severe acute kidney injury. Pediatr Nephrol. 2018;33(11):2185-91.

8. Basu RK, Kaddourah A, Goldstein SL. AWARE study investigators. Assessment of a renal angina index for prediction of severe acute kidney injury in critically ill children: a multicentre, multinational, prospective observational study. Lancet Child Adolesc Health. 2018;2(2):112-20. 
9. Gawadia J, Mishra K, Kumar M, Saikia D. Prediction of severe acute kidney injury using renal angina index in a pediatric intensive care unit. Indian Pediatr. 2019;56(8):647-52.

10. Zappitelli M, Parikh CR, Akcan-Arikan A, Washburn KK, Moffett BS, Goldstein SL. Ascertainment and epidemiology of acute kidney injury varies with definition interpretation. Clin J Am Soc Nephrol. 2008;3:948-54.

11. Sutherland SM, Zappitelli M, Alexander SR, Chua AN, Brophy PD, Bunchman TE, Hackbarth R, Somers MJ, Baum M, Symons JM, Flores FX, Benfield M, Askenazi D, Chand D, Fortenberry JD, Mahan JD, McBryde K, Blowey D, Goldstein SL. Fluid overload and mortality in children receiving continuous renal replacement therapy: the prospective pediatric continuous renal replacement therapy registry. Am J Kidney Dis. 2010;55:316-25.

12. Márquez-González H, Casanova-Bracamontes L, Muñoz-Ramírez CM Peregrino-Bejarano L, Bolaños-Téllez B, Yáñez-Gutiérrez L. Relation between fluid overload and mortality in children with septic shock. Arch Argent Pediatr. 2019;117(2):105-13.

13. Dellinger RP, Levy Mitchell M. Rhodes Andrew et al. Surviving Sepsis Campaign: international guidelines for management of severe sepsis and septic shock, 2012. Intensive Care Med. 2013;39:165-228.

14. van den Akker JP, Egal M, Groeneveld AB. Invasive mechanical ventilation as a risk factor for acute kidney injury in the critically ill: a systematic review and meta-analysis. Crit Care. 2013;17:R98.

15. Cornell TT, Selewski DT, Alten JA, Askenazi D, Fitzgerald JC, Topjian A, Holubkov R, Page K, Slomine BS, Christensen JR, Dean JM, Moler FW. Acute kidney injury after out of hospital pediatric cardiac arrest. Resuscitation. 2018;131:63-8.

16. Stanski NL, Cvijanovich NZ, Fitzgerald JC, Bigham MT, Wong HR. Genomics of pediatric septic shock investigators. Severe acute kidney injury is independently associated with mortality in children with septic shock. Intensive Care Med. 2020;46(5):1050-1.

17. Basu RK, Wang Y, Wong HR, Chawla LS, Wheeler DS, Goldstein SL. Incorporation of biomarkers with the renal angina index for prediction of severe AKI in critically ill children. Clin J Am Soc Nephrol. 2014;9(4):654-62.

18. Sethi SK, Raghunathan $V$, Shah $S$, et al. Fluid overload and renal angina index at admission are associated with worse outcomes in critically ill children. Front Pediatr. 2018;6:118.

19. Abu Zeid AM, Mohammed DY, AbdAlazeem AS, Mohammed Seddeeq ASE Elnaany AM. Urinary NGAL incorporation into renal angina index for early detection of acute kidney injury in critically ill children. J Clini Nephrol. 2019; 3:093-09.

20. Matsuura R, Srisawat N, Claure-Del Granado R, et al. Use of the renal angina index in determining acute kidney injury. Kidney Int Rep. 2018;3(3):677-83.

21. Kelm DJ, Perrin JT, Cartin-Ceba R, Gajic O, Schenck L, Kennedy CC. Fluid overload in patients with severe sepsis and septic shock treated with early goal-directed therapy is associated with increased acute need for fluidrelated medical interventions and hospital death. Shock. 2015:43(1):68-73.

22. Naveda Romero OE, Naveda Meléndez AF. Fluid overload and kidney failure in children with severe sepsis and septic shock: a cohort study. Arch Argent Pediatr. 2017;115(2):118-24.

23. Hanson HR, Carlisle MA, Bensman RS, et al. Early prediction of pediatric acute kidney injury from the emergency department: a pilot study. Am J Emerg Med. 2020

\section{Publisher's Note}

Springer Nature remains neutral with regard to jurisdictional claims in published maps and institutional affiliations.

Ready to submit your research? Choose BMC and benefit from:
- fast, convenient online submission
- thorough peer review by experienced researchers in your field
- rapid publication on acceptance
- support for research data, including large and complex data types
- gold Open Access which fosters wider collaboration and increased citations
- maximum visibility for your research: over 100M website views per year
At BMC, research is always in progress.
Learn more biomedcentral.com/submissions

